\title{
Community-Acquired Acute Bacterial Meningitis in Adults: a clinical update
}

Jayne Ellis $^{1}$, Akish Luintel ${ }^{1 *}$, Arjun Chandna ${ }^{1 *}$, Robert S Heyderman ${ }^{1,2}$

1. Hospital for Tropical Diseases, University College London Hospitals NHS Foundation Trust, London, UK

2. Division of Infection and Immunity, University College London, London, UK.

Corresponding author: Jayne P Ellis, Hospital for Tropical Diseases, University College

London Hospitals NHS Foundation Trust, London, UK. Telephone: +447920024571, Email:

j.ellis@ doctors.org.uk,

* These authors contributed equally

Running header: Acute bacterial meningitis: a clinical update

Conflicts of interest: The authors declare that they have no competing interests

Keywords: bacterial meningitis; meningitis.

Word Count: Abstract: 368, Main Text: 4,117/4,000 


\section{Abstract:}

\section{Background:}

Acute bacterial meningitis (ABM) in adults is associated with a mortality that may exceed $30 \%$. Immunisation programmes have reduced the global burden; in the UK, declining incidence but persistently high mortality and morbidity mean that clinicians must remain vigilant.

\section{Sources of data:}

A systematic electronic literature search of PubMed was performed to identify all ABM literature published within the past five years.

\section{Areas of agreement and controversy:}

Clinical features cannot reliably distinguish between ABM and other important infectious and non-infectious aetiologies. Prompt investigation and empirical treatment are imperative. Lumbar puncture (LP) and cerebrospinal fluid (CSF) microscopy, biochemistry and culture remain the mainstay of diagnosis but molecular techniques are increasingly useful. The 2016 UK joint specialist societies' guideline provides expert recommendations for the management of ABM, yet published data suggest care delivered in the UK is frequently not adherent. Anxiety regarding risk of cerebral herniation following LP, unnecessary neuroimaging, underutilisation of molecular diagnostics and suboptimal uptake of adjunctive corticosteroids compromise management.

\section{Growing points:}

There is increasing recognition that current antibiotic regimens and adjunctive therapies alone are insufficient to reduce the mortality and morbidity associated with ABM.

\section{Areas timely for developing research:}

Research should be focussed on optimisation of vaccines (e.g. pneumococcal conjugate vaccines with extended serotype coverage), targeting groups at-risk for disease and reservoirs for transmission; improving adherence to management guidelines; development of new faster, more accurate 
diagnostic platforms (e.g. novel point-of-care molecular diagnostics); and development of new adjunctive therapies (aimed at the host-inflammatory response and bacterial virulence factors). 


\section{Introduction}

$\mathrm{ABM}$ is a medical emergency associated with considerable morbidity and mortality. It is widely held that prompt recognition, appropriate investigation and treatment saves lives ${ }^{1}$.Nonetheless, even when optimal management is delivered, mortality has changed little in the last 20 years $^{2-4}$. A number of management challenges continue to exist. Here, we present a clinical update on ABM in adults for physicians (emergency medicine and acute medicine frontline staff and specialist clinicians), providing an update on the epidemiology of ABM in the UK, highlighting important advances in disease prevention, diagnosis and treatment. In the light of continuing controversy and uncertainty over the best way to reduce the high mortality, we summarise the important future research directions.

\section{Epidemiology of ABM in Adults}

Community-acquired $\mathrm{ABM}$ in adults is a relatively rare ${ }^{5}$, high-impact medical emergency in the $\mathrm{UK}^{6,5}$. Although incidence is higher in children (and highest in neonates), over half of ABM cases in England and Wales are adults ${ }^{5}$. During 2004 - 2011, the overall incidence risk of laboratoryconfirmed ABM was 1.05 per 100,000 adults $^{5}$, peaking during winter months. This incidence has remained stable over the last decade with falling numbers of pneumococcal and meningococcal meningitis cases offset by a rise in ABM due to Gram-negative Enterobacteriaceae, such as Escherichia coli and Klebsiella pneumoniae, particularly in those aged over 65 years ${ }^{5,7}$. Table 1 shows the incidence by year in England and Wales for the six main causes of acute bacterial meningitis (PHE data). 


\section{Streptococcus pneumoniae}

Streptococcus pneumoniae is the commonest cause of community-acquired ABM in adults in England and Wales, responsible for 30\% of laboratory-confirmed cases (PHE data 2017). The case-fatality ratio for pneumococcal meningitis has been estimated to be $30 \%^{8}$.

Nearly 100 different pneumococcal serotypes (based on the capsular polysaccharide) have the potential to affect humans. The current pneumococcal conjugate vaccine (PCV) used in the UK targets thirteen of the most common disease-causing serotypes. A 56\% reduction in invasive pneumococcal disease (IPD) among adults has been reported since the introduction of the PCV7 into the routine infant schedule and its replacement by PCV13 in April $2010^{9}$. This indirect protection is thought to be due to the interruption of person-to-person spread.

Continued surveillance is critical as replacement by non-vaccine pneumococcal serotypes is increasingly being reported ${ }^{9,10}$. Indeed, a rise in non-vaccine serotypes has to some extent offset the benefits of vaccine introduction ${ }^{10}$ and may explain the persistently high incidence of IPD in the elderly.

\section{Neisseria meningitidis}

Neisseria meningitidis remains the second leading cause of community-acquired ABM in adults in England and Wales, responsible for 10\% of laboratory-confirmed cases (PHE data 2017). Whilst the risk of invasive meningococcal disease (IMD) is highest in infancy, a second peak occurs between 15-19 years with incidence of 3.2 per 100,000, reducing to $0.5-0.7$ per 100,000 for those over 25 years ${ }^{11}$. Case-fatality ratios have been estimated at $7 \%{ }^{8}$ but reach $15 \%$ for those over 65 years and are higher in those with meningococcal sepsis ${ }^{11}$. 
Most Neisseria meningitidis human disease is caused by one of six serogroups (A, B, C, $\mathrm{W}, \mathrm{X}$ and $\mathrm{Y}$ ). Vaccination against meningococcus group $\mathrm{C}$ (MenC) was introduced in the UK in 1999 after MenC-related IMD had doubled during the $1990 \mathrm{~s}^{12}$. Reductions in incidence of over $97 \%$ were seen within a decade ${ }^{13}$. Today, over $75 \%$ of IMD in adults in the UK is caused by meningococcus group $\mathrm{B}(\mathrm{MenB})^{11}$, although certain groups remain at risk of MenC, for example men who have sex with men ${ }^{14,15}$.

Development and implementation of a MenB vaccine has been more challenging due to the poor immunogenicity of the serogroup B capsule, antigenic diversity, propensity for genetic recombination and uncertainties regarding impact on mucosal carriage and secular trends in MenB incidence ${ }^{16}$. In September 2015 the UK became the first country in the world to introduce the new generation of MenB vaccines into the national immunisation programme. The vaccine is anticipated to protect against $73-88 \%$ of invasive strains but ongoing surveillance will be essential to determine true vaccine effectiveness ${ }^{17}$.

Until recently IMD due to other capsular groups was uncommon in the UK. Historically, serogroup A (which causes epidemic meningitis in Africa) was prevalent in the first half of the $20^{\text {th }}$ century. More recently, outbreaks of meningococcus group W (MenW) have been associated with the Hajj pilgrimage but cases have reduced since the Saudi Arabian government has mandated vaccination with the quadrivalent ACWY vaccine for non-domestic pilgrims ${ }^{18}$. However, since 2014 the UK and several other countries have seen a dramatic increase in MenW cases, accounting for 24\% of IMD in England during 2014-15. This prompted emergency MenACWY vaccination introduction, replacing routine MenC vaccination in children 13-14 years, with a catch-up 
programme for 14-18 years and university entrants aged under 25 years. Early analyses indicate promising results ${ }^{19}$.

Both MenW and meningococcus group Y (MenY) are implicated in disease in older adults, often with other comorbidities. The incidence of invasive MenY disease has been increasing in Sweden, Canada and the US ${ }^{20}$. Historically MenY has been associated with outbreaks in care homes $^{21}$. For all serogroups, outbreaks of meningococcal meningitis are associated with higher case-fatality ratios than sporadic $\operatorname{cases}^{22}$.

\section{Other bacteria}

Most other causes of community-acquired ABM in adults occur in those with particular risk factors for immune compromise or immunosenescence such as alcohol dependency, pregnancy, diabetes mellitus, patients taking immunosuppressive medications and old age ${ }^{7}$. These include Enterobacteriaceae such as Escherichia coli and rarely Listeria monocytogenes, Haemophilus influenzae, Streptococcus agalactiae, Staphylococcus aureus ${ }^{23}$ which are associated with mortality estimates ranging from $30-60 \%{ }^{7,23,24}$.

\section{Pathogenesis}

Almost all bacteria that cause community-acquired ABM colonise mucosal surfaces and then relatively rarely, gain access to the bloodstream and then multiply in sufficient numbers to then cross the blood-brain-barrier into the CSF to cause CNS inflammation and tissue injury. Disease 
also occurs following direct bacterial translocation from the upper respiratory tract to the meninges through the cribriform plate ${ }^{25}$.

\section{Bacterial colonisation and invasion}

Colonisation requires that bacteria are able to adhere to cell surfaces and avoid both innate and adaptive host defence mechanisms. Streptococcus pneumoniae and Neisseria meningitidis are both highly successful colonisers of the human nasopharyn $x^{26}$. Following initial engagement with the upper respiratory tract mucosa via hair-like appendages called fimbriae or pili, $S$. pneumoniae binds to polymeric immunoglobulin receptors of epithelial cells via the bacterial adhesin, choline-binding protein A (CbpA); and N. meningitidis binds to host ligands such as carcinoembryonic antigen-related cell-adhesion molecule (CEACAM) molecules and cell surface integrins via opacity proteins, OpA and OpC respectively ${ }^{25}$.

Bloodstream invasion allows bacteria to reach and then cross the blood brain barrier (BBB), either transcellularly or paracellularly to the central nervous system $(\mathrm{CNS})^{25}$. Once in the subarachnoid space, the relative lack of host defence mechanisms facilitates bacterial replication. Bacterial components trigger microglia and phagocytic cells to release pro-inflammatory mediators ${ }^{27}$ such as TNF, IL-6, and IL-1B. These cause increased BBB permeability, leading to leucocyte adhesion to the BBB and invasion, thrombosis and further inflammation. 


\section{CNS inflammation and tissue injury}

CNS inflammation and disruption of the BBB results in CNS tissue damage through apoptotic neuronal injury, oedema, microvascular thrombosis and raised intracranial pressure ${ }^{28}$. The excessive neutrophil-driven inflammatory responses typical of $\mathrm{ABM}^{28}$ result in oxidative stress driving neuronal death and dysfunction ${ }^{28}$. Bacterial cell lysis in ABM, exacerbated by antibiotic treatment, releases further pro-inflammatory agents such as lipopolysaccharide, teichoic acid and peptidoglycans worsening neuronal damage ${ }^{26}$. For this reason, adjunctive steroids and other anti-inflammatory agents have been tested as part of the management of meningitis ${ }^{29}$.

\section{Clinical presentation}

Presenting features of $\mathrm{ABM}$ in adults vary according to patient age $\mathrm{e}^{30}$ and cannot reliably distinguish bacterial from viral meningitis or other differential diagnoses ${ }^{31}$. Empirical antibiotic therapy must often be commenced on the basis of suspicion whilst awaiting results of diagnostic procedures.

The most consistent clinical symptom in $\mathrm{ABM}$ is headache ${ }^{8}$, however no individual symptom can satisfactorily discriminate ABM from other conditions ${ }^{32}$. The presence of two or more of headache, neck stiffness, fever and altered consciousness, has a sensitivity of $95 \%$ for $\mathrm{ABM}^{8}$. A purpuric or petechial rash is most predictive of Neisseria meningitidis but many patients with meningococcal meningitis do not have a rash and conversely not all patients with a meningococcal rash have meningitis. In adolescents, the presence of sepsis with or without shock should raise suspicion of invasive meningococcal disease, particularly if associated with a rash. 
These patients may not always have clinical evidence of meningitis ${ }^{33,34}$. Pathognomonic clinical examination findings do not exist. Kernig's and Brudzinski's signs are often cited but their sensitivity can be as low as $5 \%{ }^{35}$.

Clinicians must therefore have a high index of suspicion of ABM in adults with a febrile illness, where there isn't an obvious focus of infection. Particularly young fit adults may appear relatively well at presentation. Parental or family concerns should not be ignored. Patients with proven ABM may have prodromal respiratory viral illnesses. ABM should be considered in anyone with a severe headache and sinusitis or acute otitis media, where it is most often associated with Streptococcus pneumoniae ${ }^{36}$. Characteristic features such as neck stiffness and headache are less frequent in the elderly, particularly those with Gram-negative bacillary meningitis (GNBM) ${ }^{7}$. These patients may present with systemic complications such as distant foci of infection or septic $\operatorname{shock}^{7}$.

Whenever a diagnosis of $\mathrm{ABM}$ is suspected, other infectious causes of meningitis (viral, mycobacterial, fungal and parasitic), brain abscesses and extra-cranial infections which can mimic ABM (pneumonia and retropharyngeal abscesses) should be considered. Immune compromise and particularly HIV infection should be ruled out, particularly where there is an unusual presentation of a common pathogen or the presentation of an unusual organism. Non-infectious mimics of ABM include sub-arachnoid haemorrhage, autoimmune syndromes, paraneoplastic syndromes, migraine and rarely medications, such as lamotrigine and cotrimoxazole ${ }^{37}$. 


\section{Nosocomial meningitis}

Nosocomial meningitis most commonly follows neurosurgical procedures and trauma. A detailed description is outwith the scope of this review. Altered mental status occurs less

frequently than in community-acquired $\mathrm{ABM}^{38}$. There is a higher incidence of GNBM including Pseudomonas aeruginosa ${ }^{7}$. Staphylococcus aureus, including methicillin-resistant strains, is more common in nosocomial meningitis associated with invasive procedures ${ }^{38}$.

\section{Confirming the diagnosis of $\mathrm{ABM}$}

Given the failure of clinical characteristics alone to discriminate ABM from other differential diagnoses ${ }^{31}$, access to and timely use of accurate microbiological diagnostics is essential. CSF microscopy, biochemistry and culture to confirm aetiology and antimicrobial susceptibility of causative pathogens remain the mainstay of diagnosis ${ }^{34}$.

\section{Timing of lumbar puncture}

An LP is essential to the investigation of patients with suspected meningitis and must be performed without delay, provided there are no specific contraindications. In a recent multicentre prospective cohort study of adults with suspected meningitis in 42 UK hospitals, the median time to LP was 17 hours (IQR 8-29) ${ }^{39}$. Delayed LPs led to a reduction in pathogen detection, increased exposure to unnecessary anti-infectives and prolonged hospital stay ${ }^{39}$.

A LP should be performed before administration of antibiotics unless there are specific neurological contraindications (see below) or evidence of severe sepsis, respiratory compromise 
or a rapidly evolving meningococcal rash, in which case empirical antibiotics should be given without delay ${ }^{34}$. LP should be performed within 1 hour of arrival at hospital provided that it is safe to do so. Treatment should be commenced immediately after the LP has been performed, and within the first hour ${ }^{34}$. CSF culture positivity rate declines by $>30 \%$ when LP is performed more than four hours after initiation of antibiotics ${ }^{40}$, however the cell count and biochemistry remain informative up to $24-72$ hours later.

\section{Neuroimaging}

In most cases of ABM neuroimaging is not indicated prior to LP and can result in delays to antibiotic therapy and increased mortality ${ }^{34}$. Neuroimaging should be performed before proceeding to LP if one or more of the following clinical signs are present: (1) focal neurological signs (2) presence of papilloedema (3) continuous or uncontrolled seizures or (4) GCS $\leq 12$ or a rapidly declining conscious level ${ }^{34}$ ). It is important to recognise that normal computerised tomography (CT) does not exclude raised intracranial pressure in the context of these warning signs. A recent prospective cohort study from the Netherlands, demonstrated cerebral herniation following LP in ABM to be a rare event. 3.1\% (47/1533) of episodes had a clinical deterioration possibly caused by LP, two patients deteriorated within 1 hour after LP $(0.1 \%)$. It remains uncertain whether LP was causal in this deterioration. Significantly, in 43 of the 47 patients with deterioration, a CT head was performed prior to LP, this highlights the lack of reliability of CT reporting of contraindications to lumbar puncture ${ }^{41}$ ). 


\section{CSF opening pressure and collection}

CSF opening pressure should be measured (unless LP is performed in seated position, which artificially raises the opening pressure), and is usually raised $(>20 \mathrm{~cm} \mathrm{H} 20)$ in $\mathrm{ABM}^{8}$. Often inappropriately small volumes of CSF are taken at LP which limits diagnostic capacity. CSF is produced at a rate of $22 \mathrm{ml} / \mathrm{hr}$ and $15 \mathrm{mls}$ or more can be taken safely ${ }^{40,41}$.

\section{CSF Biochemistry}

CSF protein, glucose (with concurrent serum glucose) and lactate should always be measured in the investigation of ABM. Typical CSF changes can help distinguish probable bacterial and viral meningitis (table 2).

\section{CSF microscopy and culture}

A raised CSF white cell count (WCC) (> 5 cells $/ \mu 1)$ with a predominance of neutrophils is typical of ABM. WCC however may be normal (especially in early disease or immunodeficiency) and lymphocytes may predominate in partially antibiotic treated ABM or Listeria monocytogenes meningitis ${ }^{44}$.

CSF microscopy and Gram staining for bacteria has a sensitivity of 50 to $99 \%$ (dependent on organism and prior antibiotics) and a specificity of $97-100 \%$ in the diagnosis of $\mathrm{ABM}^{8}$. CSF culture is subsequently required for confirmation of the causative pathogen and for antibiotic susceptibility testing. The sensitivity of CSF culture depends upon whether antibiotics were administered pre- or post-CSF collection. CSF may be rendered sterile by administration of 
empirical antibiotics, within two hours in meningococcal meningitis and within four in pneumococcal meningitis ${ }^{45}$.

\section{Molecular CSF diagnostics}

In contrast to CSF culture, polymerase chain reaction (PCR) can detect bacterial DNA in CSF for several days after antibiotics have been administered. PCR has high sensitivity (87$100 \%)$ and specificity $(98-100 \%)^{25}$. CSF PCR for S. pneumoniae and N. meningitidis should be performed in all cases of suspected $\mathrm{ABM}^{32}$. Where no causative pathogen can be identified by culture or pathogen-specific PCR, then PCR for 16 S ribosomal RNA, which targets the highly conserved 16S rRNA gene present in almost all bacteria may be useful ${ }^{32}$. As molecular diagnostics including the potential for whole genome sequencing direct from clinical samples, become more robust and more accessible, these may replace standard Gram stain and culture.

\section{Throat swab}

In relation to the diagnosis of meningococcal disease, it is important that clinicians remember to take a bacterial throat swab for microscopy and culture. This is because in the majority of cases, naso-pharyngeal meningococcal isolates from patients with suspected ABM are almost always identical to those from their blood or $\mathrm{CSF}^{34}$. Growth of the bacteria provides drug susceptibility testing and sufficient DNA for genome sequencing to evaluate vaccine coverage 34

However, given the possibility of asymptomatic meningococcal carriage in healthy persons, a positive throat swab cannot be considered a confirmatory test and should be interpreted in caution where the clinical syndrome is not compatible with ABM 


\section{Blood culture and other blood tests}

Blood cultures should be taken as routine. If taken prior to antibiotic administration, the yield can be as high as $74 \%{ }^{32}$. Meningococcal and pneumococcal PCR on blood are useful adjunctive diagnostics which are more sensitive than bacterial culture, particularly if antibiotics have already been administered ${ }^{46}$. HIV testing should be offered to all patients with suspected ABM. The use of serum procalcitonin measurement remains limited due to cost but where available, has been reported to have a sensitivity of $\sim 95 \%$ and a specificity of $\sim 100 \%$ in distinguishing bacterial from viral meningitis in adults ${ }^{47}$.

\section{Treatment}

It is essential that patients with suspected $\mathrm{ABM}$ are stabilised rapidly and appropriate investigations obtained without delay. Empirical antibiotics should be administered immediately after LP. A user-friendly management algorithm has been developed through a collaboration between several UK specialist societies to support a more unified approach to the management of $\mathrm{ABM}^{34}$.

\section{Antibiotics}

The choice of antibiotics in ABM is a three-stage process. Empirical antibiotics should be given based on clinical suspicion, antibiotic choice may then be modified with the results of the CSF gram stain (if positive), followed by a definitive antibiotic regimen based on CSF culture and susceptibilities if available. In presence of a suggestive CSF profile but the absence of a 
confirmatory diagnostic, choice of definitive antibiotic therapy should be guided by up to date information on relative prevalence of bacterial meningitis pathogens and other patient specific factors e.g. age and co-morbidities.

The recommended empirical regimen in the UK is a third-generation cephalosporin (ceftriaxone or cefotaxime) which has bactericidal activity for both Streptococcus pneumoniae and Neisseria meningitidis, whilst achieving good CNS penetration ${ }^{26}$. If there is a history of anaphylaxis to penicillins or cephalosporins, IV chloramphenicol $25 \mathrm{mg} / \mathrm{kg} 6$ hourly can be given $^{34}$. Amoxicillin 2 grams, 4-hourly should be added if the patients are at-risk of Listeria monocytogenes meningitis ${ }^{25}$.

Resistance to penicillin resulting in treatment failure is rare for S. pneumoniae and extremely rare for $N$. meningitidis in the UK. However, in patients who have recently travelled abroad, the empirical regimen should be discussed with an infection specialist. Generally, if there is concern about resistance, vancomycin $15-20 \mathrm{mg} / \mathrm{kg} 12$-hourly or rifampicin $600 \mathrm{mg}$ BD is administered alongside empirical ceftriaxone or cefotaxime . Cephalosporins should be continued with vancomycin as CNS penetration of vancomycin is suboptimal ${ }^{34}$.

The definitive antibiotic regimens that target the isolated bacteria are summarised in table 3.

\section{Duration of therapy}

There is little evidence to guide duration of antibiotics for ABM outside paediatric trials. A meta-analysis of all-cause ABM in children demonstrated non-inferiority between 4-7 days and 7-14 days of treatment ${ }^{48}$. A study on IMD showed three days of benzylpenicillin treatment 
was sufficient ${ }^{49}$. Therefore the duration of antibiotics in adults is based largely on expert opinion and is dependent on the organism isolated and clinical response (table 3). Listeria ABM is recommended to be treated for 21 days but again there is no available trial data to support this recommendation ${ }^{34}$.

\section{Adjunctive corticosteroids}

Corticosteroids improve outcomes in ABM, due to reduction in inflammation ${ }^{34}$. Initial trials in children illustrated benefit in $H$. influenzae meningitis, with reduction in hearing $\operatorname{loss}^{50}$. A Dutch multi-centre trial of adult ABM showed reduction in mortality particularly in pneumococcal meningitis ${ }^{51}$.

A subsequent meta-analysis investigating corticosteroid use showed no difference in mortality, but some improvement in hearing $\operatorname{loss}^{52}$. However, the data was heterogeneous including studies from both high- and low-resource settings. The 2015 Cochrane review showed severe hearing loss was significantly reduced by corticosteroids, this was especially true in high income countries. Subgroup analysis in this data showed a significant reduction in mortality in $S$ pneumoniae meningitis but not in $N$. meningitidis or H. influenzae meningitis ${ }^{53}$.

Current recommendations are that Dexamethasone 10mg QDS should be prescribed empirically (within 12 hours of the first dose of antibiotics for suspected ABM and should continue for four days if Streptococcus pneumoniae meningitis is confirmed ${ }^{34}$.

There remains concern that corticosteroids reduce the permeability of the BBB and therefore reduce concentrations of antibiotics within the $\mathrm{CSF}^{29}$. However, given that current recommended parenteral doses of antibiotics for ABM achieve CSF concentrations well above 
the minimum inhibitory concentrations (MICs) for all of the typical ABM causative pathogens, it is doubtful that any reduction in BBB permeability mediated by dexamethasone would result in a clinically significantly reduction in antibiotic efficacy and therefore adjunctive corticosteroids should not be withheld based on this concern alone ${ }^{29}$..

\section{Other adjunctive therapies}

Numerous adjunctive interventions have shown promise in tissue culture and animal models ${ }^{29}$. These adjunctive therapies typically target the host-inflammatory response and bacterial virulence factors. Matrix metalloproteinases (MMPs) are key immune mediators that promote BBB disruption, and brain injury; doxycycline is as an effective MMP-inhibitor and in animal models, when given as an adjunct alongside ceftriaxone, has been shown to downregulate CSF inflammation leading to reduced mortality and attenuated hearing loss ${ }^{54}$. Rifampicin although bacteriostatic has significant anti-inflammatory properties and has also shown promise

as a potential adjunct in human studies ${ }^{55,56}$. Adjunctive magnesium which targets pneumococcal pneumolysin-driven neuronal injury was associated with improved survival in mice with pneumococcal meningitis ${ }^{57}$. To date, however, there is a lack of clinical trial data in humans and therefore insufficient evidence to recommend these interventions in routine clinical care.

\section{Outpatient antibiotic therapy services}

Except for chloramphenicol, oral switches do not achieve sufficient antibiotic levels in the CSF and therefore intravenous continuation therapy via outpatient antibiotic therapy (OPAT) 
services is increasingly being used for management of ABM . Benefits include reduced costs, shorter inpatient stays, fewer nosocomial infections, and increased patient satisfaction ${ }^{58}$.

The 2016 UK joint specialist societies' guideline on the diagnosis and management of acute meningitis suggest that $\mathrm{ABM}$ can be managed in an outpatient setting if, based on CSF culture and drug susceptibility testing, a suitable antibiotic is identified, and patient specific criteria for safe OPAT management are met:

1. Afebrile and clinically improving

2. Have received 5 days of inpatient management

3. Have reliable intravenous access

4. Be able to access medical advice/care from the OPAT team $24 \mathrm{~h}$ a day

5. Have no other acute medical needs other than for parenteral antimicrobials ${ }^{34}$. Suggested OPAT regimes are:

- Ceftriaxone 2g BD IV (Ceftriaxone 4g OD can be used after the first 24 hours of therapy)

- Ceftriaxone 2g BD IV and Rifampicin 600mg BD for penicillin resistant pneumococci

\section{Antimicrobial prophylaxis for contacts}

Contact tracing and the community public health management of suspected bacterial meningitis should be managed by the appropriate health protection teams; all suspected cases of ABM should be notified to the local Health Protection Unit (HPU). 


\section{Prophylaxis for $N$. meningitidis contacts}

Secondary cases of IMD are estimated to occur in 2-4 per 1,000 cases of close contacts ${ }^{34}$. Most patients with meningococcal meningitis have become colonized with the causative bacteria in the preceding seven days, therefore household contacts as well as "kissing contacts" should receive prophylaxis ${ }^{34}$. Antibiotics should be given to healthcare staff only if they have been in close contact with a confirmed case of meningococcal disease, for example, if they have been heavily exposed to respiratory secretions or droplets from intubation or whilst performing cardiopulmonary resuscitation ${ }^{34}$. Vaccination should be offered to any unvaccinated contacts of cases for non-group B serogroup . Close contacts have an increased risk of IMD for six months following exposure and GPs should be alerted to this possibility ${ }^{34}$.

\section{Prophylactic regimens}

- 500mg ciprofloxacin STAT for Adults (>12 years)

- 250mg ciprofloxacin STAT for children (5-12 years)

- $30 \mathrm{mg} / \mathrm{kg}$ ciprofloxacin STAT up to $125 \mathrm{mg}$ stat for children (< 5 years)

Where ciprofloxacin is contraindicated, rifampicin can be given as an alternative.

Close contacts of pneumococcal meningitis are not thought to have any increased risk therefore no prophylaxis is indicated except in an institutional outbreak setting. 


\section{Future directions}

Early diagnosis, rapid diagnostics and appropriate clinical management are essential to minimise the risk of poor outcomes in ABM. Despite the existence of widely available national guidelines on meningitis case management ${ }^{34}$, published data suggest that the clinical care delivered in the UK remains suboptimal. Inappropriate neuroimaging leads to delays in LP and antibiotic administration. Suboptimal use of molecular diagnostics and HIV-testing have also been highlighted as areas for improvement ${ }^{39,59-61}$. A national audit to evaluate current meningitis management across the UK is ongoing and will provide important up-to-date data on clinical care.

Delayed LPs in particular have been shown to be associated with increased mortality in $\mathrm{ABM}^{62}$. The potential impact of the four-hour Emergency Department targets has been cited as possible explanation for LP delay ${ }^{39}$. Physicians' fear of cerebral herniation following LP, leading to unnecessary neuroimaging, is also an important factor ${ }^{63}$. Several studies demonstrate that complications following LP in ABM are extremely rare and there is little evidence that the two are causally related ${ }^{41}$. Education programs for frontline emergency and acute physicians to emphasise the urgency and importance of LPs are urgently required. Whether a protocolised, goal-directed therapy approach would improve outcomes in ABM in the UK is yet to be evaluated.

There is a clear need to improve on current diagnostics in ABM, particularly in the era of increased prior antibiotics and anti-microbial resistance (AMR). In the report from McGill et al

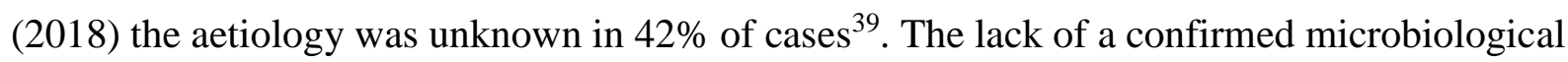
diagnosis, impedes pathogen-directed therapies, increases exposure to unnecessary broad spectrum anti-infectives, potentially worsens outcomes and hinders trials of new treatments. 
Optimisation of point-of-care PCR diagnostics, transcriptomics research to identify RNA signatures associated with $\mathrm{ABM}$ and loop-mediated isothermal amplification-based assays ${ }^{64}$ may each play a role. However, it is the expanded use of whole genome sequencing in clinical care as it becomes increasingly rapid, accessible, affordable and directly applicable to clinical specimens without the need for culture, that has the greatest potential to transform meningitis diagnostics, particularly prediction of genotypic drug resistance ${ }^{65}$.

Further research is also required into adjunctive therapies alongside antibiotics to limit neuronal injury and improve outcomes. Although several potential targets and interventions have been tested in animal models ${ }^{57}$ and small retrospective human studies ${ }^{55}$, robust multinational multi-centre randomised clinical trials in humans will be required for their formal evaluation.

Finally, the antigenic diversity of S. pneumoniae and $N$. meningitidis challenges the success of current vaccines and particularly the generation of herd protection through the interruption of carriage and so person-to-person spread. Pneumococcal conjugate vaccines with extended serotype coverage are being developed alongside new vaccines containing conserved Streptococcus pneumoniae proteins. Such vaccines have the potential to reduce the risk of serotype replacement and vaccine escape by providing pan-serotype pneumococcal protection. Data on whether the recently introduced protein-based MenB vaccine prevents nasopharyngeal carriage has been conflicting to date. A large UK-wide study to evaluate the effect of immunisation on nasopharyngeal carriage has just started recruiting (ISRCTN75858406) and will provide important data on the ability of the MenB vaccine to generate herd protection in the UK. 


\title{
Conclusions
}

\author{
$\mathrm{ABM}$ is an uncommon disease which continues to be associated with considerable \\ morbidity and mortality amongst adults in the UK. In the context of changing epidemiology and \\ the emergence of AMR, clinical diagnosis remains challenging and prompt comprehensive \\ investigation is required to maximise diagnostic potential and to deliver optimal targeted therapy. \\ Further research is required in how best to improve diagnosis and clinical care in the UK \\ alongside the testing of adjunctive therapies to further improve outcomes.
}

\section{Acknowledgements}

We would like to thanks Dr Mary Ramsay and her team for providing the acute bacterial meningitis incidence data for England \& Wales. 
Tables:

Table 1: Incidence per 100000 people of the main causes of laboratory confirmed acute bacterial meningitis in adults in England and Wales, 20132017 (Data from Public Health England)*.

\begin{tabular}{|c|c|c|c|c|c|}
\hline & \multicolumn{5}{|c|}{ Annual Incidence } \\
\hline & 2013 & 2014 & 2015 & 2016 & 2017 \\
\hline Streptococcus pneumoniae & 0.12 & 0.13 & 0.17 & 0.18 & 0.18 \\
\hline Neisseria meningitidis & 0.05 & 0.05 & 0.06 & 0.06 & 0.06 \\
\hline Escherichia coli & 0.05 & 0.07 & 0.06 & 0.04 & 0.07 \\
\hline Haemophilus influenzae & 0.02 & 0.02 & 0.02 & 0.01 & 0.02 \\
\hline Listeria monocytogenes & 0.02 & 0.03 & 0.02 & 0.01 & 0.02 \\
\hline Streptococcus agalactiae & 0.01 & 0.01 & 0.01 & 0.01 & 0.01 \\
\hline
\end{tabular}


Table 2: CSF features typical of bacterial, viral, tuberculous and fungal meningitis.

\begin{tabular}{|c|c|c|c|c|c|}
\hline & Normal & Bacterial & Viral & Tuberculous & Fungal \\
\hline $\begin{array}{l}\text { Opening } \\
\text { pressure }(\mathrm{cm} \\
\text { CSF })\end{array}$ & $12-20$ & Raised & $\begin{array}{l}\text { Normal / mildly } \\
\text { raised }\end{array}$ & Raised & Raised \\
\hline Appearance & Clear & Turbid & Clear & $\begin{array}{l}\text { Clear / cloudy / } \\
\text { haemorrhagic }\end{array}$ & Clear / cloudy \\
\hline $\begin{array}{l}\text { CSF WCC } \\
(\text { cells/ } \mu \mathrm{l})\end{array}$ & $<5$ & $\begin{array}{l}\text { Raised } \\
(10-10,000, \\
\text { typically } \\
>100)\end{array}$ & $\begin{array}{l}\text { Raised } \\
\text { (typically 5-1000) }\end{array}$ & $\begin{array}{l}\text { Raised } \\
\text { (typically 5- } \\
500 \text { ) }\end{array}$ & $\begin{array}{l}\text { Raised } \\
\text { (typically 5- } \\
500 \text { ) }\end{array}$ \\
\hline $\begin{array}{l}\text { Predominant cell } \\
\text { type }\end{array}$ & NA & Neutrophils & Lymphocytes* & Lymphocytes** & Lymphocytes \\
\hline $\begin{array}{l}\text { CSF protein } \\
(\mathrm{g} / \mathrm{L})\end{array}$ & $<0.4$ & Raised & Mildly raised & $\begin{array}{l}\text { Markedly } \\
\text { raised }\end{array}$ & Raised \\
\hline $\begin{array}{l}\text { CSF glucose } \\
(\mathrm{mmol})\end{array}$ & $2.6-4.5$ & Low & $\begin{array}{l}\text { Normal / slightly } \\
\text { low }\end{array}$ & Very low & Low \\
\hline $\begin{array}{l}\text { CSF/plasma } \\
\text { glucose ratio }\end{array}$ & $>0.66$ & Low & $\begin{array}{l}\text { Normal / slightly } \\
\text { low }\end{array}$ & Very low & Low \\
\hline
\end{tabular}


Table 3: Antibiotic treatment regimens recommended to common ABM causative pathogens Recommended antibiotic regimen including first line therapy, alternative regimen in case of contraindications to first line treatment options and duration of treatment ${ }^{34}$

\begin{tabular}{|c|c|c|c|c|}
\hline Causative pathogen & Gram Stain & Antibiotics & $\begin{array}{l}\text { Penicillin allergy / } \\
\text { Alternative regimen }\end{array}$ & $\begin{array}{l}\text { Recommended } \\
\text { Duration }\end{array}$ \\
\hline $\begin{array}{r}\text { Streptococcus } \\
\text { Pneumoniae }\end{array}$ & $\begin{array}{l}\text { Gram Positive } \\
\text { Diplococci }\end{array}$ & $\begin{array}{l}\text { Cefotaxime } 2 \mathrm{~g} \\
6 \text { hrly or } \\
\text { Ceftriaxone } \\
2 \mathrm{~g} \mathrm{BD}\end{array}$ & $\begin{array}{l}\text { Chloramphenicol } \\
25 \mathrm{mg} / \mathrm{kg}, 6 \mathrm{hrly}\end{array}$ & $\begin{array}{l}\geq 10 \text { days (up to } \\
14 \text { days } \\
\text { dependent on } \\
\text { clinical response) }\end{array}$ \\
\hline $\begin{array}{r}\text { Neisseria } \\
\text { Meningitidis }\end{array}$ & $\begin{array}{l}\text { Gram negative } \\
\text { Diplococci }\end{array}$ & $\begin{array}{l}\text { Cefotaxime } 2 \mathrm{~g} \\
6 \text { hly or } \\
\text { Ceftriaxone } \\
2 \mathrm{~g} \mathrm{BD}\end{array}$ & $\begin{array}{l}\text { Chloramphenicol } \\
25 \mathrm{mg} / \mathrm{kg}, 6 \mathrm{hrly}\end{array}$ & 5 days \\
\hline $\begin{array}{r}\text { Listeria } \\
\text { Monocytogenes }\end{array}$ & $\begin{array}{l}\text { Gram Positive } \\
\text { Rods }\end{array}$ & $\begin{array}{l}\text { Amoxicillin } 2 \mathrm{~g} 4 \\
\text { hourly }\end{array}$ & $\begin{array}{l}\text { Cotrimoxazole } 10- \\
20 \mathrm{mg} / \mathrm{kg} \text { in } 4 \text { divided } \\
\text { doses }\end{array}$ & 21 days \\
\hline
\end{tabular}


Table 4: Common management pitfalls encountered in the management of patients with acute bacterial meningitis

\section{Management pitfall:}

- Unnecessary neuroimaging prior to lumbar punctures remains common

- Significant delays in lumbar punctures result in:

- Reduced pathogen detection

- Increased exposure to anti-infectives

- Increased duration of hospital stays

- Increased mortality

- Often inappropriately small volumes of $\mathrm{CSF}$ are taken at lumbar puncture which limits diagnostic capacity.

- Suboptimal HIV testing

- Suboptimal use of molecular diagnostics

\section{Clinical guidelines:}

- Neuroimaging should only be performed before proceeding to LP if one or more of the following clinical signs is present: (1) focal neurological signs (2) presence of papilloedema (3) continuous or uncontrolled seizures or (4) GCS $\leq 12$

- Lumbar puncture should be performed without delay in patients with suspected meningitis unless the criteria for neuroimaging is met.

- A lumbar puncture should be performed before administration of antibiotics unless there is evidence of severe sepsis or a rapidly evolving meningococcal rash in which case empirical antibiotics should not be delayed (REF).

- CSF is produced at a rate of $22 \mathrm{ml} / \mathrm{hr}$ and up to $15 \mathrm{mls}$ can be taken safely

- All patients with meningitis should be offered an HIV test.

- All patients with suspected meningitis should have:

- Blood sent for Pneumococcal and meningococcal PCR

- CSF sent for Pneumococcal and meningococcal PCR

- If no aetiology is identified on culture or pathogen specific PCR testing, and ABM remains likely, then $16 \mathrm{~S}$ rRNA PCR should be performed on CSF. 
Acknowledgements: We would like to thank Dr Mary Ramsay, Director of the Health

Protection Research Unit in Immunisation at Public Health England for the epidemiology data provided and her support in writing this manuscript. 


\section{References}

1. McGill F, Heyderman RS, Panagiotou S, Tunkel AR, Solomon T. Acute bacterial meningitis in adults. Lancet. 2016;388(10063):3036-3047. doi:10.1016/S01406736(16)30654-7.

2. Durand ML, Calderwood SB, Weber DJ, et al. Acute Bacterial Meningitis in Adults -- A Review of 493 Episodes. N Engl J Med. 1993;328(1):21-28.

doi:10.1056/NEJM199301073280104.

3. Polkowska A, Toropainen M, Ollgren J, Lyytikäinen O, Nuorti JP. Bacterial meningitis in Finland, 1995-2014: a population-based observational study. BMJ Open. 2017;7(5):e015080. doi:10.1136/bmjopen-2016-015080.

4. van de Beek D, de Gans J, Spanjaard L, Weisfelt M, Reitsma JB, Vermeulen M. Clinical Features and Prognostic Factors in Adults with Bacterial Meningitis. N Engl J Med. 2004;351(18):1849-1859. doi:10.1056/NEJMoa040845.

5. Okike IO, Ribeiro S, Ramsay ME, Heath PT, Sharland M, Ladhani SN. Trends in bacterial, mycobacterial, and fungal meningitis in England and Wales 2004-11: an observational study. Lancet Infect Dis. 2014;14(4):301-307. doi:10.1016/S14733099(13)70332-3.

6. Gjini AB, Stuart JM, Lawlor DA, et al. Changing epidemiology of bacterial meningitis among adults in England and Wales 1991-2002. Epidemiol Infect. 2006;134(3):567. doi:10.1017/S0950268805005595.

7. Pomar V, Benito N, López-Contreras J, Coll P, Gurguí M, Domingo P. Spontaneous 
gram-negative bacillary meningitis in adult patients: characteristics and outcome. $B M C$ Infect Dis. 2013;13(1):451. doi:10.1186/1471-2334-13-451.

8. van de Beek D, de Gans J, Spanjaard L, Weisfelt M, Reitsma JB, Vermeulen M. Clinical Features and Prognostic Factors in Adults with Bacterial Meningitis. N Engl J Med. 2004;351(18):1849-1859. doi:10.1056/NEJMoa040845.

9. Waight PA, Andrews NJ, Ladhani SN, Sheppard CL, Slack MPE, Miller E. Effect of the 13-valent pneumococcal conjugate vaccine on invasive pneumococcal disease in England and Wales 4 years after its introduction: an observational cohort study. Lancet Infect Dis. 2015;15(5):535-543. doi:10.1016/S1473-3099(15)70044-7.

10. Feikin DR, Kagucia EW, Loo JD, et al. Serotype-Specific Changes in Invasive Pneumococcal Disease after Pneumococcal Conjugate Vaccine Introduction: A Pooled Analysis of Multiple Surveillance Sites. Viboud C, ed. PLoS Med. 2013;10(9):e1001517. doi:10.1371/journal.pmed.1001517.

11. Ladhani SN, Flood JS, Ramsay ME, et al. Invasive meningococcal disease in England and Wales: Implications for the introduction of new vaccines. Vaccine. 2012;30(24):37103716. doi:10.1016/j.vaccine.2012.03.011.

12. Miller E, Salisbury D, Ramsay M. Planning, registration, and implementation of an immunisation campaign against meningococcal serogroup C disease in the UK: a success story. Vaccine. 2001;20 Suppl 1:S58-67. http://www.ncbi.nlm.nih.gov/pubmed/11587814. Accessed November 14, 2018.

13. Campbell H, Borrow R, Salisbury D, Miller E. Meningococcal C conjugate vaccine: The experience in England and Wales. Vaccine. 2009;27:B20-B29. 
doi:10.1016/j.vaccine.2009.04.067.

14. Folaranmi TA, Kretz CB, Kamiya H, et al. Increased Risk for Meningococcal Disease Among Men Who Have Sex With Men in the United States, 2012-2015. Clin Infect Dis. 2017;65(5):756-763. doi:10.1093/cid/cix438.

15. Bozio CH, Blain A, MacNeil J, et al. Meningococcal Disease Surveillance in Men Who Have Sex with Men - United States, 2015-2016. MMWR Morb Mortal Wkly Rep. 2018;67(38):1060-1063. doi:10.15585/mmwr.mm6738a4.

16. Pollard AJ, Riordan A, Ramsay M. Group B meningococcal vaccine: recommendations for UK use. Lancet. 2014;383(9923):1103-1104. doi:10.1016/S0140-6736(14)60226-9.

17. Parikh SR, Andrews NJ, Beebeejaun K, et al. Effectiveness and impact of a reduced infant schedule of $4 \mathrm{CMenB}$ vaccine against group B meningococcal disease in England: a national observational cohort study. Lancet (London, England). 2016;388(10061):27752782. doi:10.1016/S0140-6736(16)31921-3.

18. Hajj 1439 H. - Health Regulations. https://www.moh.gov.sa/en/hajj/pages/healthregulations.aspx. Accessed November 14, 2018.

19. Campbell H, Edelstein M, Andrews N, Borrow R, Ramsay M, Ladhani S. Emergency Meningococcal ACWY Vaccination Program for Teenagers to Control Group W Meningococcal Disease, England, 2015-2016. Emerg Infect Dis. 2017;23(7):1184-1187. doi:10.3201/eid2307.170236.

20. Säll O, Stenmark B, Glimåker M, et al. Clinical presentation of invasive disease caused 
by Neisseria meningitidis serogroup Y in Sweden, 1995 to 2012. Epidemiol Infect. 2017;145(10):2137-2143. doi:10.1017/S0950268817000929.

21. Gunaratnam P, Massey P, Durrheim D, Torvaldsen S. Invasive meningococcal disease in elderly people, New South Wales, Australia, 1993 to 2012. West Pacific Surveill response J WPSAR. 4(4):4-10. doi:10.5365/WPSAR.2013.4.4.001.

22. Brooks R, Woods CW, Benjamin, Jr. DK, Rosenstein NE. Increased Case-Fatality Rate Associated with Outbreaks of Neisseria meningitidis Infection, Compared with Sporadic Meningococcal Disease, in the United States, 1994-2002. Clin Infect Dis. 2006;43(1):4954. doi:10.1086/504804.

23. Domingo P, Pomar V, de Benito N, Coll P. The spectrum of acute bacterial meningitis in elderly patients. BMC Infect Dis. 2013;13(1):108. doi:10.1186/1471-2334-13-108.

24. Koopmans MM, Bijlsma MW, Brouwer MC, van de Beek D, van der Ende A. Listeria monocytogenes meningitis in the Netherlands, 1985-2014: A nationwide surveillance study. J Infect. 2017;75(1):12-19. doi:10.1016/j.jinf.2017.04.004.

25. McGill F, Heyderman RS, Panagiotou S, Tunkel AR, Solomon T. Acute bacterial meningitis in adults. Lancet (London, England). 2016;388(10063):3036-3047. doi:10.1016/S0140-6736(16)30654-7.

26. Gerber J, Nau R. Mechanisms of injury in bacterial meningitis. Curr Opin Neurol. 2010;23(3):312-318. doi:10.1097/WCO.0b013e32833950dd.

27. Sheu J-N, Liao W-C, Wu U-I, et al. Resveratrol suppresses calcium-mediated microglial activation and rescues hippocampal neurons of adult rats following acute bacterial 
meningitis. Comp Immunol Microbiol Infect Dis. 2013;36(2):137-148.

doi:10.1016/j.cimid.2012.11.002.

28. Doran KS, Fulde M, Gratz N, et al. Host-pathogen interactions in bacterial meningitis. Acta Neuropathol. 2016;131(2):185-209. doi:10.1007/s00401-015-1531-z.

29. Nau R, Djukic M, Spreer A, Ribes S, Eiffert H. Bacterial meningitis: an update of new treatment options. Expert Rev Anti Infect Ther. 2015;13(11):1401-1423. doi:10.1586/14787210.2015.1077700.

30. Magazzini S, Nazerian P, Vanni S, et al. Clinical picture of meningitis in the adult patient and its relationship with age. Intern Emerg Med. 2012;7(4):359-364. doi:10.1007/s11739012-0765-1.

31. Khatib U, van de Beek D, Lees JA, Brouwer MC. Adults with suspected central nervous system infection: A prospective study of diagnostic accuracy. J Infect. 2017;74(1):1-9. doi:10.1016/j.jinf.2016.09.007.

32. Granier S, Owen P, Pill R, Jacobson L. Recognising meningococcal disease in primary care: qualitative study of how general practitioners process clinical and contextual information. BMJ. 1998;316(7127):276-279. http://www.ncbi.nlm.nih.gov/pubmed/9472513. Accessed November 14, 2018.

33. Stephens DS, Greenwood B, Brandtzaeg P. Epidemic meningitis, meningococcaemia, and Neisseria meningitidis. Lancet. 2007;369(9580):2196-2210. doi:10.1016/S01406736(07)61016-2.

34. McGill F, Heyderman RS, Michael BD, et al. The UK joint specialist societies guideline 
on the diagnosis and management of acute meningitis and meningococcal sepsis in immunocompetent adults. J Infect. 2016;72(4):405-438. doi:10.1016/j.jinf.2016.01.007.

35. Brouwer MC, Thwaites GE, Tunkel AR, van de Beek D. Dilemmas in the diagnosis of acute community-acquired bacterial meningitis. Lancet. 2012;380(9854):1684-1692. doi:10.1016/S0140-6736(12)61185-4.

36. Kaplan DM, Gluck O, Kraus M, Slovik Y, Juwad H. Acute bacterial meningitis caused by acute otitis media in adults: A series of 12 patients. Ear Nose Throat J. 2017;96(1):20-28. http://www.ncbi.nlm.nih.gov/pubmed/28122100. Accessed November 14, 2018.

37. Simms KM, Kortepeter C, Avigan M. Lamotrigine and aseptic meningitis. Neurology. 2012;78(12):921-927. doi:10.1212/WNL.0b013e31824c4634.

38. Kumari VHB, Babu AR, Srinivas D, Siddaiah N, Somanna S. Methicillin-Resistant Staphylococcus aureus central nervous system infections - Analysis and outcome. Br J Neurosurg. 2015;29(3):413-418. doi:10.3109/02688697.2015.1006168.

39. McGill F, Griffiths MJ, Bonnett LJ, et al. Incidence, aetiology, and sequelae of viral meningitis in UK adults: a multicentre prospective observational cohort study. Lancet Infect Dis. 2018;18(9):992-1003. doi:10.1016/S1473-3099(18)30245-7.

40. Nigrovic LE, Malley R, Macias CG, et al. Effect of Antibiotic Pretreatment on Cerebrospinal Fluid Profiles of Children With Bacterial Meningitis. Pediatrics. 2008;122(4):726-730. doi:10.1542/peds.2007-3275.

41. Costerus JM, Brouwer MC, Sprengers MES, Roosendaal SD, van der Ende A, van de Beek D. Cranial Computed Tomography, Lumbar Puncture, and Clinical Deterioration in 
Bacterial Meningitis: A Nationwide Cohort Study. Clin Infect Dis. 2018;67(6):920-926. doi:10.1093/cid/ciy200.

42. Rubin RC, Henderson ES, Ommaya AK, Walker MD, Rall DP. The Production of Cerebrospinal Fluid in Man and Its Modification by Acetazolamide. J Neurosurg. 1966;25(4):430-436. doi:10.3171/jns.1966.25.4.0430.

43. Huang T-Y, Chung H-W, Chen M-Y, et al. Supratentorial Cerebrospinal Fluid Production Rate in Healthy Adults: Quantification with Two-dimensional Cine Phase-Contrast MR Imaging with High Temporal and Spatial Resolution. Radiology. 2004;233(2):603-608. doi:10.1148/radiol.2332030884.

44. Arevalo CE, Barnes PF, Duda M, Leedom JM. Cerebrospinal fluid cell counts and chemistries in bacterial meningitis. South Med J. 1989;82(9):1122-1127. http://www.ncbi.nlm.nih.gov/pubmed/2772683. Accessed November 14, 2018.

45. Kanegaye JT, Soliemanzadeh P, Bradley JS. Lumbar puncture in pediatric bacterial meningitis: defining the time interval for recovery of cerebrospinal fluid pathogens after parenteral antibiotic pretreatment. Pediatrics. 2001;108(5):1169-1174. http://www.ncbi.nlm.nih.gov/pubmed/11694698. Accessed November 14, 2018.

46. Newcombe J, Cartwright K, Palmer WH, McFadden J. PCR of peripheral blood for diagnosis of meningococcal disease. J Clin Microbiol. 1996;34(7):1637-1640. http://www.ncbi.nlm.nih.gov/pubmed/8784560. Accessed November 14, 2018.

47. Morales Casado MI, Moreno Alonso F, Juárez Belaunde AL, Heredero Gálvez E, Talavera Encinas O, Julián-Jiménez A. Capacidad de la procalcitonina para predecir meningitis bacterianas en el servicio de urgencias. Neurología. 2016;31(1):9-17. 
doi:10.1016/J.NRL.2014.07.003.

48. Karageorgopoulos DE, Valkimadi PE, Kapaskelis A, Rafailidis PI, Falagas ME. Short versus long duration of antibiotic therapy for bacterial meningitis: a meta-analysis of randomised controlled trials in children. Arch Dis Child. 2009;94(8):607-614. doi:10.1136/adc.2008.151563.

49. Ellis-Pegler R, Galler L, Roberts S, Thomas M, Woodhouse A. Three days of intravenous benzyl penicillin treatment of meningococcal disease in adults. Clin Infect Dis. 2003;37(5):658-662. doi:10.1086/377203.

50. Havens PL, Wendelberger KJ, Hoffman GM, Lee MB, Chusid MJ. Corticosteroids as adjunctive therapy in bacterial meningitis. A meta-analysis of clinical trials. Am J Dis Child. 1989;143(9):1051-1055. http://www.ncbi.nlm.nih.gov/pubmed/2773883. Accessed November 14, 2018.

51. de Gans J, van de Beek D, European Dexamethasone in Adulthood Bacterial Meningitis Study Investigators. Dexamethasone in adults with bacterial meningitis. $N$ Engl J Med. 2002;347(20):1549-1556. doi:10.1056/NEJMoa021334.

52. van de Beek D, Farrar JJ, de Gans J, et al. Adjunctive dexamethasone in bacterial meningitis: a meta-analysis of individual patient data. Lancet Neurol. 2010;9(3):254-263. doi:10.1016/S1474-4422(10)70023-5.

53. Brouwer MC, McIntyre P, Prasad K, van de Beek D. Corticosteroids for acute bacterial meningitis. Cochrane database Syst Rev. 2015;(9):CD004405.

doi:10.1002/14651858.CD004405.pub5. 
54. Meli DN, Coimbra RS, Erhart DG, et al. Doxycycline Reduces Mortality and Injury to the Brain and Cochlea in Experimental Pneumococcal Meningitis. Infect Immun. 2006;74(7):3890-3896. doi:10.1128/IAI.01949-05.

55. Bretonnière $\mathrm{C}$, Jozwiak $\mathrm{M}$, Girault $\mathrm{C}$, et al. Rifampin use in acute community-acquired meningitis in intensive care units: the French retrospective cohort ACAM-ICU study. Crit Care. 2015;19(1):303. doi:10.1186/s13054-015-1021-7.

56. Uppal L, Singhi S, Singhi P, Aggarwal R. Role of Rifampin in Reducing Inflammation and Neuronal Damage in Childhood Bacterial Meningitis. Pediatr Infect Dis J. 2017;36(6):556-559. doi:10.1097/INF.0000000000001513.

57. Hupp S, Ribes S, Seele J, et al. Magnesium therapy improves outcome in Streptococcus pneumoniae meningitis by altering pneumolysin pore formation. Br J Pharmacol. 2017;174(23):4295-4307. doi:10.1111/bph.14027.

58. Paladino JA, Poretz D. Outpatient parenteral antimicrobial therapy today. Clin Infect Dis. 2010;51 Suppl 2(S2):S198-208. doi:10.1086/653520.

59. Cullen MM. An audit of the investigation and initial management of adults presenting with possible bacterial meningitis. J Infect. 2005;50(2):120-124.

doi:10.1016/j.jinf.2003.11.016.

60. Michael B, Menezes BF, Cunniffe J, et al. Effect of delayed lumbar punctures on the diagnosis of acute bacterial meningitis in adults. Emerg Med J. 2010;27(6):433-438. doi:10.1136/emj.2009.075598.

61. Stockdale AJ, Weekes MP, Aliyu SH. An audit of acute bacterial meningitis in a large 
teaching hospital 2005-10. QJM. 2011;104(12):1055-1063. doi:10.1093/qjmed/hcr123.

62. Proulx N, Frechette D, Toye B, Chan J, Kravcik S. Delays in the administration of antibiotics are associated with mortality from adult acute bacterial meningitis. QJM. 2005;98(4):291-298. doi:10.1093/qjmed/hci047.

63. Costerus JM, Brouwer MC, van de Beek D. Technological advances and changing indications for lumbar puncture in neurological disorders. Lancet Neurol. 2018;17(3):268278. doi:10.1016/S1474-4422(18)30033-4.

64. Seki M, Kilgore PE, Kim EJ, Ohnishi M, Hayakawa S, Kim DW. Loop-Mediated Isothermal Amplification Methods for Diagnosis of Bacterial Meningitis. Front Pediatr. 2018;6:57. doi:10.3389/fped.2018.00057.

65. Guo L, Li Y, Liu L, et al. Next-Generation Sequencing Could be a Promising Diagnostic Approach for Pathogen Detection: Pathogenic Analysis of Pediatric Bacterial Meningitis by Next-Generation Sequencing Technology Directly from Cerebrospinal Fluid Specimens. bioRxiv. June 2018:340273. doi:10.1101/340273. 